\title{
Population Dynamics and Agglomeration Factors: A Non-Linear Threshold Estimation of Density Effects
}

\author{
Mariateresa Ciommi ${ }^{1}$, Gianluca Egidi ${ }^{2}$, Rosanna Salvia ${ }^{3}{ }^{(D}$, Sirio Cividino ${ }^{4}$, Kostas Rontos ${ }^{5}$ and \\ Luca Salvati ${ }^{6,7, *}$ \\ 1 Department of Economic and Social Science, Polytechnic University of Marche, Piazza Martelli 8, \\ I-60121 Ancona, Italy; m.ciommi@univpm.it \\ 2 Department of Agricultural and Forestry Sciences (DAFNE), Tuscia University, Via San Camillo de Lellis, \\ I-01100 Viterbo, Italy; egidi.gianluca@unitus.it \\ 3 Department of Mathematics, Computer Science and Economics, University of Basilicata, Viale dell'Ateneo \\ Lucano, I-85100 Potenza, Italy; rosanna.salvia@unibas.it \\ 4 Department of Agriculture, University of Udine, Via del Cotonificio 114, I-33100 Udine, Italy; \\ civsirio@tiscali.it \\ 5 Department of Sociology, School of Social Sciences, University of the Aegean, EL-81100 Mytilene, Greece; \\ k.rontos@soc.aegean.gr \\ 6 Department of Economics and Law, University of Macerata, Via Armaroli 43, I-62100 Macerata, Italy \\ 7 Global Change Research Institute of the Czech Academy of Sciences, Lipová 9, CZ-37005 České Budějovice, \\ Czech Republic \\ * Correspondence: luca.salvati@crea.gov.it or luca.salvati@unimc.it
}

Received: 14 February 2020; Accepted: 11 March 2020; Published: 13 March 2020

check for updates

\begin{abstract}
Although Southern Europe is relatively homogeneous in terms of settlement characteristics and urban dynamics, spatial heterogeneity in its population distribution is still high, and differences across regions outline specific demographic patterns that require in-depth investigation. In such contexts, density-dependent mechanisms of population growth are a key factor regulating socio-demographic dynamics at various spatial levels. Results of a spatio-temporal analysis of the distribution of the resident population in Greece contributes to identifying latent (density-dependent) processes of metropolitan growth over a sufficiently long time interval (1961-2011). Identification of density-dependent patterns of population growth contributes to the analysis of socioeconomic factors underlying demographic divides, possibly distinguishing between the effects of population concentration and dispersion. Population growth rates were non-linearly correlated with population density, highlighting a positive (or negative) impact of urban concentration on demographic growth when population is lower (or higher) than a fixed threshold (2800 and 1300 inhabitants $/ \mathrm{km}^{2}$ in 1961 and 2011, respectively). In a context of low population density (less than 20 inhabitants $/ \mathrm{km}^{2}$ ), the relationship between density and growth was again negative, contrasting with the positive and linear relationship observed in denser contexts. This result evidences a sort of 'depopulation' trap that leads to accelerated population decline under a defined density threshold. An improved understanding of density-dependent mechanisms of population growth and decline contributes to rethinking strategies of sustainable development and social policies more adapted to heterogeneous regional contexts.
\end{abstract}

Keywords: density-growth curve; urban expansion; municipalities; indicators; Mediterranean Europe

\section{Introduction}

Globalization, structural economic change and accelerated demographic dynamics have been demonstrated to affect urban expansion at the continental and country scales [1-4]. In advanced economies, local-scale population density and the related demographic trends are considered as 
relevant variables in the recent evolution of metropolitan agglomerations and rural districts [4-11]. In these regards, demographic dynamics, local development, and socioeconomic divides are regarded as intimately interconnected issues [12-15], whose complexity requires a long-term investigation of the representative socioeconomic contexts at different geographical scales [16].

A number of interpretative models investigating human population dynamics were based on density-independence [17]. These models assume that (i) population growth rates were dependent on the environment rather than on population density, and that (ii) density independence is a time-invariant property of the given demographic system [18]. However, as humans are uniquely able to consciously alter their environment to increase its carrying capacity [19], density dependent processes affecting population growth rates are quite common in specific socioeconomic and territorial conditions, requiring the use of transition models that simulate how density and population growth rates change over time, e.g., recalculating growth rates as a function of the relevant density component [20]. There are many kinds of density-dependent processes, which can be differentiated according to effect, cause, response, mechanism and severity [21]. Positive density-dependence (or density-dependent facilitation), describes a situation where population growth is facilitated by increased population density [22]. Negative density-dependence (or density-dependent restriction) describes a situation where population growth is curtailed by crowding [23].

Empirical investigations of density-dependent processes of population growth have reported mixed effects (both positive and negative) mediated by specific density thresholds, and the negative effects of density dependence are usually better known than the positive ones [24]. As a matter of fact, overcoming density-dependent limits on human population growth has intrinsic costs in terms of e.g., congestion, pollution, and social conflicts for the use of land and natural resources [25-27]. Positive density-dependent effects never regulate population density, as is inherent in all positive feedback mechanisms, which magnify their effects [22]. These processes are considered to be unstable and less predictable, as they tend to change towards density independence or negative interactions in a relatively rapid time span [28]. Negative density dependence can also lead to unstable population dynamics [29], especially in a context of settlement dispersion leading to (reversible) population shrinkage or irreversible processes of extinction from a given place [30].

A relatively vast consensus has been reached in the analysis of density values that determine urban congestion [31]. In these cases, urban concentration and settlement compactness are responsible for a slowdown of population growth rates compared with urban contexts where density is below that threshold $[3,32,33]$ and which display comparatively higher growth rates $[1,7,34]$. Less information is available on the reverse mechanism, i.e., a positive (or negative) regulation of population growth at low densities [28]. In these cases, it is reasonable to hypothesize that rural districts with particularly low densities experience negative population growth rates more frequently than rural districts with a higher resident population concentration [35]. Particularly low density and continuous population decline are symptoms of depopulation [36-38]. A refined, comparative analysis of demographic dynamics over a sufficiently long time interval and a detailed enough spatial scale seems to be appropriate for identifying density thresholds [39-41] that more likely lead to positive (or negative) growth rates in both urban contexts (e.g., congestion effects) and rural contexts (e.g., depopulation effects).

Comparing local-scale demographic trends in homogeneous socioeconomic contexts (e.g., a country or a set of regions with similar characteristics, including the socioeconomic structure, history, and political/cultural background) provides specific knowledge in the analysis of latent mechanisms of population growth, thereby underlying both processes of urban expansion and rural development [42-46]. While being informative of regional growth trends, a comparative, local-scale analysis of demographic dynamics along the whole urban-rural gradient is still only partially complete in many European countries $[25,33,47,48]$. By considering both urban and rural dynamics over a long time span, this type of empirical analyses reveal latent socioeconomic transformations and give precise information on the density-dependent mechanisms of population growth, leading to identification of distinctive models of urban expansion/shrinkage and rural development/collapse [13,49-51]. 
A wealth of factors were demonstrated to shape the spatial distribution of resident population in Europe in conditions of both high and low density [52-55]. In this continent, a relatively complex economic cycle took place in the aftermath of World War II, together greatly influencing urban expansion and rural development [56-58]. While compact urbanization driven by internal (rural-urban) migration was associated with high population densities [59-62], residential mobility to suburban areas led to discontinuous urban expansion in more recent times, fueling economic growth in intermediate (non-urban, non-rural) locations [63-66]. Suburbanization in turn influenced metropolitan structures and socioeconomic functions, determining population decline in many urban cores and an unexpected expansion in more peripheral districts $[6,39,52,67-70]$. Based on these premises, a better investigation of density-dependent mechanisms of population growth along the entire urban-rural gradient in a given country (i.e., considering the whole range of population densities at a very local scale) may provide a basic, integrated knowledge of apparent (or latent) processes of urban concentration/deconcentration in metropolitan regions and rural depopulation in more marginal districts. This knowledge also evidences spatio-temporal convergences or divergences in demographic dynamics leading to more cohesive settlements or consolidating territorial disparities and economic polarization in dense-dynamic regions and depopulation-disadvantaged areas $[22,29,40]$.

The Mediterranean basin is considered to be a paradigmatic region in Europe showing homogeneous population dynamics and compact-dense urban structures [71]. The urban population in this region has grown from 89 million inhabitants in 1950 to 258 million inhabitants in 1995, and is expected to reach more than 400 million inhabitants in 2030 [10,58,72]. The Mediterranean urban population is largely concentrated in major countries such as Italy, Spain, France, and Greece. In 1995, urbanization rates ranged between 59.2\% (Greece) and 76.5\% (Spain), and will increase (more or less markedly) by the year 2030. The socioeconomic and territorial processes that occur when demographic growth rates are regulated by the size of a population in a given amount of resources have been relatively poorly investigated in this region. In contrast, analysis of density-dependent population dynamics fills a gap in the current literature on the role of agglomeration factors in the formation and consolidation of Mediterranean settlements.

By adopting municipalities as the elementary analysis unit, the impact of density-dependent mechanisms of population growth was investigated in our study by using a non-linear estimation of the role of urban concentration in demographic increase (or decline) at five time intervals in Greece [73-75]. Under the hypothesis that countries in Southern Europe have displayed similar demographic dynamics in the aftermath of World War II (e.g., hyper-concentration in urban areas fueled by rural-urban migration with the consequent depopulation of rural districts [58]), results of the present study may highlight internal and external factors shaping local-scale demographic growth rates [69] along the entire density gradient, from urban to rural areas. Assuming that local-scale population growth is positively correlated with urban concentration, demographic dynamics were assumed to shape spatial divides with distinctive temporal patterns and intensity [27,76-78]. In this way, the results of an exploratory analysis of local-scale population dynamics may inform strategies of urban planning/containment and rural development which are better adapted to changing socioeconomic contexts $[8,56,79]$.

\section{Density-dependent Population Growth and the Spatial Distribution of Settlements}

Density-dependent mechanisms regulating population growth are an important factor whose local- and regional-scale influence on the spatial distribution of human settlements in metropolitan regions and rural districts were (and still are) widely discussed [10]. Density-dependent mechanisms of population growth (or decline) are relatively well studied in non-human populations [80], and reflect particularly complex regulatory processes at the community level [81-83]. For human populations, analysis of density-dependent mechanisms of demographic dynamics is relatively more difficult because of the inherent complexity of the background context and the wealth of socioeconomic factors and constraints influencing settlement density [84]. 
Assuming spatial variability in population growth rates as a density-dependent process [85], the relationship between population growth and demographic density was tested in this study. Our work hypothesizes a non-linear relationship between demographic density and population growth [23], in line with earlier evidence of density-dependent population dynamics (Figure 1). Non-linearity in the relationship between the two variables reflects the distinctive action of density thresholds in population growth (or decline), implying complex effects and more volatile interactions over space between economic factors and the background social context [3,39,41]. More specifically, population growth rates under equilibrium conditions were assumed to increase with urban concentration (i.e., high population density) up to a specific density threshold, progressively decreasing for higher values of population density (e.g., reflecting over-crowded settlements). This assumption paralleled urban growth models envisaging agglomeration benefits for a level of concentration below a critical threshold, and negative externalities from urban congestion for concentrations above a critical threshold $[1,7,33]$.

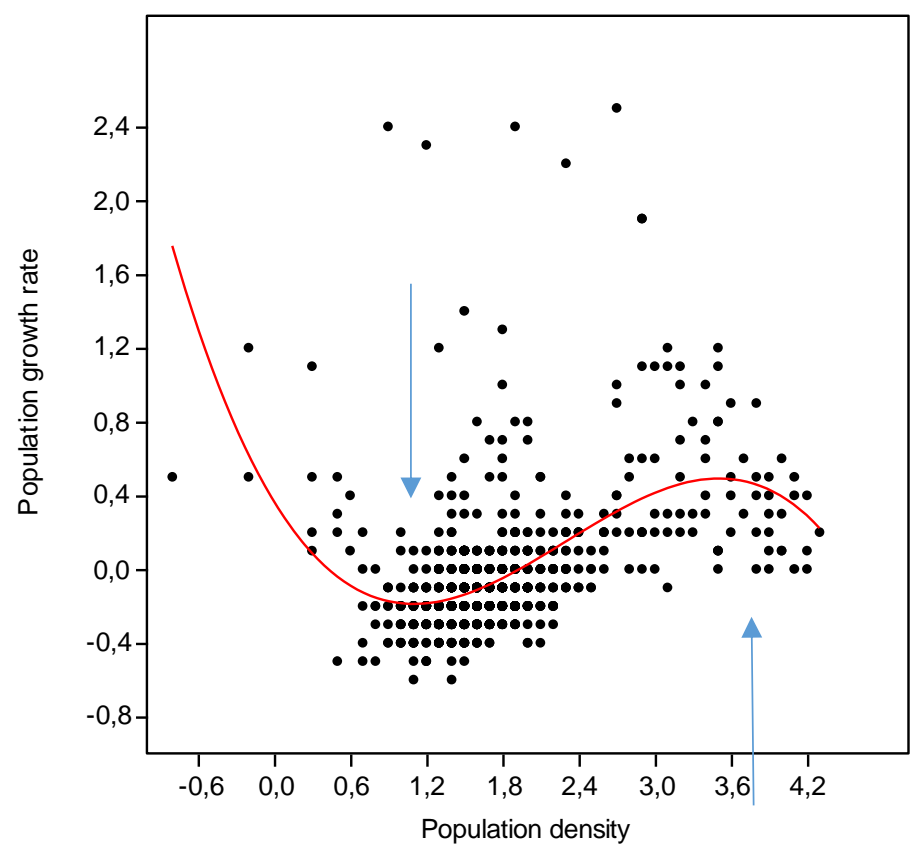

Figure 1. A graphical hypothesis on the relationship between population growth rate and population density (logarithm) in the study area (1034 Greek municipalities during the decade 2001-2011). Arrows indicate empirical (critical) thresholds for depopulation (left) and urban congestion (right).

We also hypothesized the presence of additional, critical thresholds that distinguish the positive effects of medium-density agglomeration on urban growth from a sort of 'depopulation trap' [28]. In local contexts characterized by a persistently low population density, the relationship between demographic growth and urban concentration was no longer positive, while becoming heterogeneous, less predictable and, in some cases, negative [36]. Depopulation of rural areas is a widespread phenomenon that has occurred in advanced economies, especially in countries with a long established rural tradition, such as in Southern Europe [37]. To identify the main trends in the dynamics of rural populations in the Central Pyrenees in the last century, Alados et al. [38] used density independent and density dependent models, testing a power law distribution of population size over a long time interval. According to Alados et al. [38], "populations exhibited density-dependent positive feedback between 1960 and 2010, and a long-term positive correlation between agricultural activity and population size, which has resulted in a free-scale population distribution that has been disrupted by the collapse of the traditional agricultural society and by emigration to the industrialized cities". In this context, negative density-dependent regulation of population growth in hyper-rural districts can contribute to disruptive population collapses, which can be identified by changes in the spatial pattern of population 
distribution [86]. These reflect complex socio-ecological systems that have strong feedback mechanisms assuring (or undermining in some cases) their intrinsic regulation [87].

The socioeconomic system analyzed in our study is considered in dynamic equilibrium, being continuously influenced by a set of endogenous and exogenous factors [85]. Assuming each year studied as representative of dynamic equilibrium conditions, a comparative analysis of 5 different intervals covering a time window of 50 years allows identification of intrinsic and stable factors in the given settlement model and the possible factors of discontinuity and imbalance at the same time [35]. Based on non-linear modeling, results of the empirical analysis identify density thresholds showing a possible turnaround in population growth rates (from positive to negative or the reverse in areas with population density above or below a given threshold). Comparing the critical density thresholds between time intervals allows a refined inference on the socioeconomic processes underlying the density-dependent relationship between population density and growth across the entire metropolitan hierarchy $[29,40,88]$. In this context, analysis of the entire urban-rural gradient in a given country (considering urban and rural municipalities together), allows the identification of different density thresholds, evidencing divergent demographic dynamics at both high and low density. This investigation contributes to clarifying the role of demographic dynamics in both urban contexts with population concentration/shrinkage and in highly depopulated rural contexts, thus evidencing coordinated/uncoordinated mechanisms of population growth [21]. This approach is original since it integrates, for the first time to our knowledge, a refined investigation of urban cycles (e.g., urbanization vs. suburbanization) with basic evidence on rural development.

Given the amplitude of recent urban transformations [63], density-dependent population dynamics have been relatively poorly investigated across European regions $[14,53,89]$. Since homogeneous databases with representative data at disaggregated spatial scales are rather scarce in Europe, and often need standardization, validation and control procedures [51,57,76], testing density-dependent population dynamics in a given country may benefit from the operational definition of Territorial Statistical Units developed by Eurostat. Considering municipalities as the elementary analysis unit, Eurostat made a relatively vast and stabilized amount of demographic data from national censuses available for the last five decades (1961-2011), allowing appropriate within-region comparisons of population dynamics. In Mediterranean Europe, a paradigmatic region with homogeneous demographic dynamics and urban structures, high variability in the spatial distribution of resident population reveals characteristic demographic patterns at local scale. These patterns reflect a spatial structure of settlements centered on dense, central locations intrinsically distinct from the dispersed and discontinuous settlements typical of rural areas.

\section{Methodology}

\subsection{Study Area}

In this study, long-term demographic dynamics in Greece were considered as representative of more general population trends in Southern Europe. While displaying heterogeneous population dynamics at the local scale, with different population size across municipalities, the Greek settlement model was regarded as being spatially polarized and intrinsically compact-dense, basically centered on the capital city (Athens) and the surrounding region. Greece-like other Mediterranean countries-has very dense urban agglomerations and depopulated rural areas, displaying highly variable rates of population growth over time [70]. The Local Administrative Units (LAU) introduced by Eurostat for statistical purposes were adopted in this study as the elementary analysis unit (Figure 2). LAUs are the basic elements of NUTS (Nomenclature of Territorial Statistical Units), and include spatial units that are fully representative of local communities administered by homogeneous authorities (municipalities, 'communes', or equivalent units). LAUs play a key role in official statistics because of data availability from national censuses and relevance for policy implementation. Eurostat disseminated a homogenized list of spatial units and boundaries for regional comparisons, together with a collection of population 
data derived from national censuses carried out every 10 years at each LAU unit for six time points encompassing 50 years between 1961 and 2011. Population figures were recalculated for the most recent administrative boundaries (2011) and interpolated for the 1961-2011 census period.

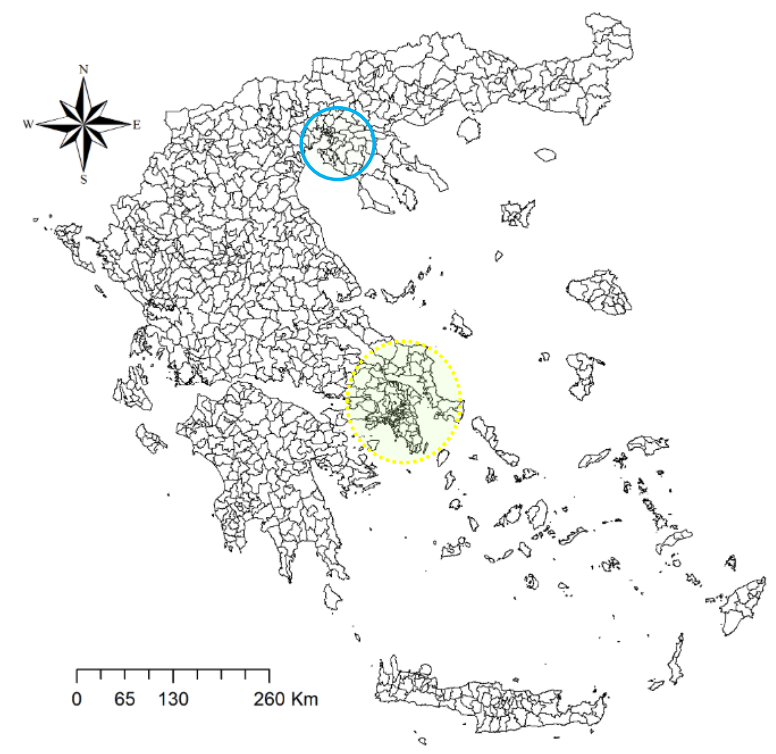

Figure 2. A map of Greek municipalities (circles indicate the metropolitan region of Athens in yellow, and the Salonika province in blue).

\subsection{Data and Indicators}

Population data were analyzed using spreadsheets, and illustrated through maps produced with ArcMap software (ESRI, Redwoods, USA) using a shapefile of Greek municipalities provided by Eurostat. Two indicators were adopted in this study: (i) population density, calculated as the ratio of resident population in the municipal area $\left(\mathrm{km}^{2}\right)$; and (ii) per cent annual change in the resident population (1961-1971, 1971-1981, 1981-1991, 1991-2001, 2001-2011). Scatter plots were used to investigate the relationship between population density and annual (per cent) rate of growth by year.

\subsection{Statistical Analysis}

The intrinsic properties of the empirical distribution of population density at the municipal scale in Greece (representative of the spatial distribution of settlements) were studied separately for each year through descriptive statistics (elaborating both central tendency and dispersion measures) and diversity indexes. Being derived from the ecological literature, these metrics provide a comprehensive analysis of dominance, diversification (Simpson, Brillouin, Menhinick and Margalef indexes), and homogeneity (Pielou evenness and equitability) of settlements in the area, while considering the spatial variability in population density across Greek municipalities. The relationship between population growth $(\mathrm{Y})$ and demographic density $(X)$ was analyzed separately for each time window testing 5 equations (with $a_{j}$ and e being the estimation coefficients and the random effect, respectively) reflecting a specific empirical relationship between growth and density:

- a linear form hypothesizing a unique effect-positive or negative-of population concentration on demographic dynamics (growth or decline) along the entire density gradient based on the following equation:

$$
\mathrm{Y}=\mathrm{a}_{0}+\mathrm{a}_{1} \mathrm{X}+\mathrm{e}
$$

- a quadratic form assuming a divergent effect of population density on growth rates below (or above) a defined threshold:

$$
\mathrm{Y}=\mathrm{a}_{0}+\mathrm{a}_{1} \mathrm{X}+\mathrm{a}_{2} \mathrm{X}^{2}+\mathrm{e}
$$


- a cubic form assuming two divergent effects of population density on growth rates below (or above) two thresholds:

$$
\mathrm{Y}=\mathrm{a}_{0}+\mathrm{a}_{1} \mathrm{X}+\mathrm{a}_{2} \mathrm{X}^{2}+\mathrm{a}_{3} \mathrm{X}^{3}+\mathrm{e}
$$

- more complex polynomial forms (forth- and fifth-grade) assuming multiple, divergent effects of population density on growth rates below (or above) defined thresholds:

$$
\begin{gathered}
Y=a_{0}+a_{1} X+a_{2} X^{2}+a_{3} X^{3}+a_{4} X^{4}+e \\
Y=a_{0}+a_{1} X+a_{2} X^{2}+a_{3} X^{3}+a_{4} X^{4}+a_{5} X^{5}+e .
\end{gathered}
$$

Forms (4-5) predict a particularly volatile relationship between population density and growth and should be considered as intrinsic controls in the experiment. A best-fit non-linear estimation of the equations (1-5) using empirical data was evaluated using two performance metrics (adjusted $R^{2}$ and Fisher-Snedecor F statistic) for each equation. The best model was chosen that maximizes the explained variance (F statistic) taking account of the degrees of freedom (the number of estimated parameters, ranging from 2 in the linear form to 6 in the fifth-grade polynomial form). Coefficients representing the most performing model were reported separately for each year. Population density was log-transformed prior to analysis. In the case of polynomial models, density thresholds were derived in correspondence of a local peak (or low) of the estimated function for each time interval. Local peaks at high density (or at low density) were considered indicative of the effect of urban concentration (or depopulation) above (or below) a given density threshold. The population growth rate (per cent annual) corresponding with any function's peak (or low) was derived from the estimated equation coefficients separately for each time interval.

\section{Results}

Table 1 describes the main properties of the statistical distribution of population density on a municipal scale in Greece for 6 years of study, from 1961 to 2011. Against a constant increase in the average values, a more contained increase in the median, which justifies a progressive decline in the median-mean ratio, indicates a substantial and persistent deviation from normality. The standard error of the average increased up to 2001, and then decreased moderately in 2011. The same temporal pattern was observed for the geometric average. For all the years investigated, the spatial distribution of population density was largely asymmetric, as the skewness and kurtosis indices clearly suggest. However, both indices tend to decline over time.

The minimum and maximum density values confirm a spatial polarization in hyper-compact and dense urban areas and in hyper-rural, low-density areas. The two most relevant percentiles (25th and 75th) show a trend towards densification of rural municipalities (with a density slightly less than 100 inhabitants $/ \mathrm{km}^{2}$ ), while a more discontinuous trend was observed for hyper-rural municipalities. Finally, the coefficient of variation tended to decrease progressively, especially in the last two decades. A similar trend was observed for the dominance index. A value close to zero indicates a statistical distribution dominated by a small number of elements. In our case, this translates into a few municipalities with a high density (mainly in the metropolitan region of Attica and in the Salonika's province) and in many rural municipalities with a low and very low density scattered across the mountain districts of the country. According to Simpson diversity and Pielou equitability, the difference in density values on a local scale increased slightly over time. A similar trend (reverse scale) was observed for Margalef's and Menhinick's diversity indexes. 
Table 1. Descriptive analysis of the statistical distribution of population density (inhabitants $/ \mathrm{km}^{2}$ ) in Greek municipalities $(\mathrm{n}=1034)$ by year.

\begin{tabular}{ccccccc}
\hline Metric & $\mathbf{1 9 6 1}$ & $\mathbf{1 9 7 1}$ & $\mathbf{1 9 8 1}$ & $\mathbf{1 9 9 1}$ & $\mathbf{2 0 0 1}$ & $\mathbf{2 0 1 1}$ \\
\hline Statistical indices & & & & & & \\
Mean & 373 & 486 & 612 & 650 & 693 & 695 \\
Standard error & 52.0 & 66.9 & 83.9 & 83.7 & 85.4 & 81.7 \\
Median & 41.6 & 36.7 & 36.7 & 38.2 & 39.9 & 35.0 \\
Minimum & 0.2 & 0.3 & 0.3 & 0.7 & 1.2 & 1.1 \\
Maximum & 19,809 & 24,650 & 36,781 & 34,431 & 34,106 & 29,976 \\
Median-to-mean ratio & 0.11 & 0.08 & 0.06 & 0.06 & 0.06 & 0.05 \\
Coefficient of & 4.48 & 4.43 & 4.41 & 4.14 & 3.96 & 3.78 \\
variation & 26.5 & 22.2 & 21.2 & 21.6 & 21.6 & 17.4 \\
25th percentile & 76.5 & 69.6 & 74.5 & 80.2 & 91.2 & 93.5 \\
75th percentile & 7.2 & 6.7 & 6.9 & 6.4 & 6.0 & 5.5 \\
Skewness & 59.6 & 51.4 & 59.9 & 49.7 & 44.8 & 36.2 \\
Kurtosis & 54.1 & 49.4 & 51.2 & 55.0 & 59.1 & 53.0 \\
Geometric mean & & & & & & \\
Diversity indices & 0.020 & 0.020 & 0.020 & 0.018 & 0.016 & 0.015 \\
Dominance index & 0.98 & 0.98 & 0.98 & 0.98 & 0.98 & 0.99 \\
Simpson diversity & 4.64 & 4.53 & 4.50 & 4.59 & 4.66 & 4.71 \\
Brillouin diversity & 1.67 & 1.46 & 1.30 & 1.26 & 1.22 & 1.22 \\
Menhinick diversity & 80.31 & 78.69 & 77.33 & 76.99 & 76.62 & 76.61 \\
Margalef diversity & 0.10 & 0.09 & 0.09 & 0.10 & 0.10 & 0.11 \\
Evenness (Pielou) & 0.67 & 0.65 & 0.65 & 0.66 & 0.67 & 0.68 \\
Equitability (Pielou) & 0.65 &
\end{tabular}

The homogeneity in the statistical distribution of the density values according to Pielou evenness assumes a U-shaped trend, with the greatest heterogeneity observed in 1981, corresponding with the greatest population concentration and maximum urban-rural polarization. Brillouin's diversity followed a similar pattern. In general, the descriptive statistics show some significant trends over time: (i) an increase in the average density and population disparities along the urban-rural gradient; (ii) the highest urban polarization in 1981; (iii) faster population loss in small municipalities, especially in the 2000s. Greek municipalities were classified according with 8 fixed classes of population density (Table 2). The most frequent classes are those with a density between 25 and 50 inhabitants $/ \mathrm{km}^{2}$ and between 50 and 100 inhabitants $/ \mathrm{km}^{2}$. In both cases, however, the number of municipalities belonging to these two classes decreased progressively from around 60\% in 1961 to $40 \%$ in 2011 . The classes that grew the most are those with low density $\left(10-25\right.$ inhabitants $\left./ \mathrm{km}^{2}\right)$ and high density $\left(>1000\right.$ inhabitants $\left./ \mathrm{km}^{2}\right)$. This suggests a marked polarization in urban and rural areas.

Table 2. Per cent distribution of municipalities in Greece $(n=1034)$ by year and density class (inhabitants $/ \mathrm{km}^{2}$ ).

\begin{tabular}{ccccccc}
\hline Density & $\mathbf{1 9 6 1}$ & $\mathbf{1 9 7 1}$ & $\mathbf{1 9 8 1}$ & $\mathbf{1 9 9 1}$ & $\mathbf{2 0 0 1}$ & $\mathbf{2 0 1 1}$ \\
\hline$<10$ & 3.8 & 6.6 & 8.2 & 7.4 & 7.1 & 12.1 \\
$10-25$ & 17.9 & 23.8 & 23.0 & 23.8 & 24.6 & 26.3 \\
$25-50$ & 37.5 & 33.3 & 31.5 & 29.0 & 27.3 & 23.0 \\
$50-100$ & 23.1 & 19.1 & 18.1 & 18.7 & 18.0 & 14.7 \\
$100-250$ & 8.6 & 7.4 & 7.6 & 8.2 & 9.5 & 9.4 \\
$250-500$ & 1.8 & 1.9 & 3.2 & 3.5 & 2.7 & 3.0 \\
$500-1000$ & 1.7 & 1.4 & 1.0 & 1.6 & 2.5 & 2.4 \\
$>1000$ & 5.5 & 6.6 & 7.4 & 7.7 & 8.4 & 9.1 \\
\hline
\end{tabular}

Urban-rural polarization in Greece can be more effectively described with the results of a quantitative analysis of the spatial distribution of the population residing in the main urban areas of the country (Table 3). While consolidated urban areas (central municipalities of Piraeus, Athens and Salonika) began to lose population in 1961, 1971, and 1981, respectively, peri-urban areas around these cities have consolidated their demographic dimensions. The metropolitan area of Athens (outside 
the Greater Athens' area) and Salonika's province were the districts that have attracted part of the population from the rest of the country (69\% of the population in 1961, 55\% in 2011) and abroad during the entire study period. Density differentials have followed this trend. Central cities had the highest population density in the country, decreasing slightly in the last few decades. Intermediate (non-urban, non-rural) areas settled on fairly high (and continuously growing) density values. Rural and inland areas stably stagnated on density values lower than 50 inhabitants $/ \mathrm{km}^{2}$.

Table 3. Per cent share of resident population in total Greek population by district and year.

\begin{tabular}{ccccccc}
\hline District & $\mathbf{1 9 6 1}$ & $\mathbf{1 9 7 1}$ & $\mathbf{1 9 8 1}$ & $\mathbf{1 9 9 1}$ & $\mathbf{2 0 0 1}$ & $\mathbf{2 0 1 1}$ \\
\hline Per cent share of population & in country & population & & & & \\
Athens & 7.5 & 9.9 & 9.1 & 7.5 & 6.8 & 6.1 \\
Piraeus & 2.3 & 2.1 & 2.0 & 1.8 & 1.6 & 1.5 \\
Greater Athens * & 12.2 & 16.7 & 19.7 & 20.3 & 20.2 & 20.4 \\
Athens metro ** & 2.2 & 2.8 & 3.4 & 4.4 & 5.4 & 6.3 \\
Attica *** & 0.4 & 0.4 & 0.4 & 0.3 & 0.3 & 0.3 \\
Salonika & 3.0 & 3.9 & 4.2 & 3.7 & 3.3 & 2.9 \\
Salonika metro **** & 3.5 & 4.2 & 4.8 & 5.5 & 6.3 & 7.2 \\
Rest of Greece **** & 68.9 & 60.0 & 56.5 & 56.4 & 56.0 & 55.3 \\
Population density & & & & & & \\
Athens & 16,113 & 22,234 & 22,735 & 19,824 & 19,142 & 17,065 \\
Piraeus & 16,948 & 16,760 & 17,543 & 16,317 & 15,694 & 14,478 \\
Greater Athens * & 3052 & 4390 & 5751 & 6217 & 6621 & 6680 \\
Athens metro ** & 71 & 92 & 125 & 172 & 224 & 262 \\
Attica *** & 44 & 42 & 44 & 42 & 48 & 45 \\
Salonika & 13,699 & 18,864 & 22,262 & 20,962 & 19,872 & 17,192 \\
Salonika metro **** & 81 & 100 & 126 & 154 & 189 & 216 \\
Rest of Greece ***** & 46 & 42 & 44 & 47 & 49 & 49 \\
\hline
\end{tabular}

* except for the municipalities of Athens and Piraeus; ${ }^{* *}$ except for the municipalities of the Greater Athens' area; *** except for the municipalities of the Athens' metropolitan region; ${ }^{* * * *}$ except for the municipality of Salonika; ****** except for Attica and Salonika province.

On the basis of these results, density maps (Figure 3) show a particularly aggregated distribution of resident population across Greek regions. The most evident density increases were observed in urban and peri-urban areas (Athens and Salonika, Crete, coastal Peloponnese, Central-Western Macedonia). In the inner areas, isolated medium-high density settlements were intermixed with extensive hyper-rural districts with a very low population density. Despite rapid population growth, the Greek urban system at the beginning of the study (1961) consolidated in the following decades, maintaining a mono-centric structure gravitating on Athens. 


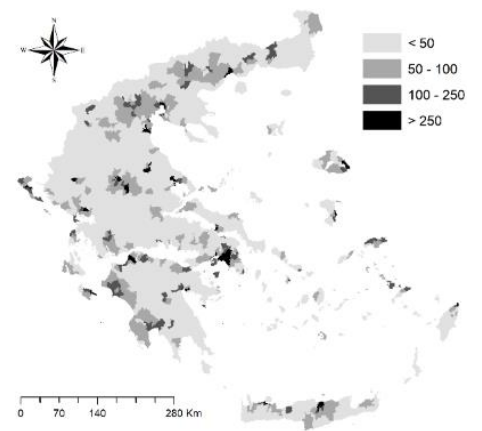

1961

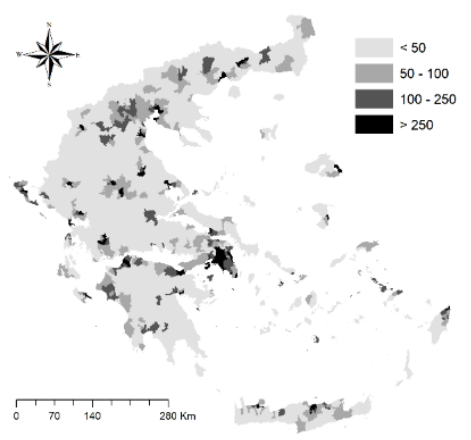

1991

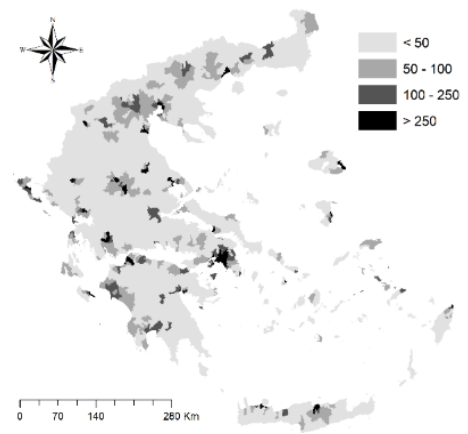

1971

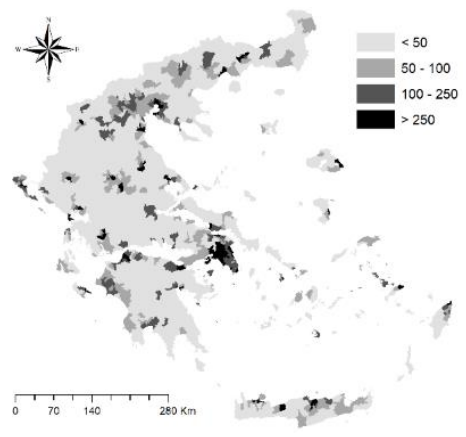

2001

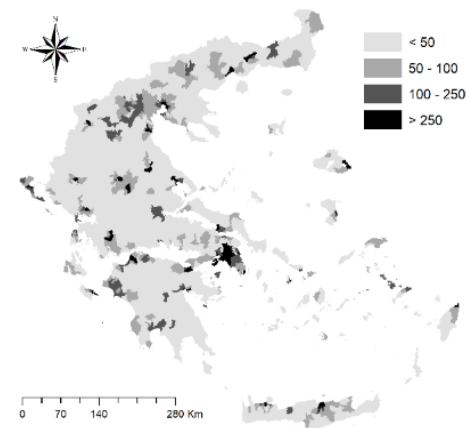

1981

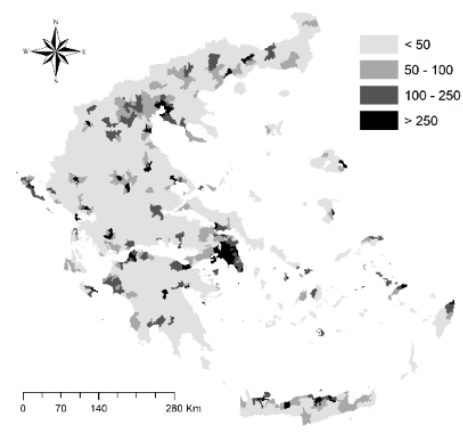

2011

Figure 3. Population density (inhabitants $/ \mathrm{km}^{2}$ ) in Greek municipalities by year.

The maps shown in Figure 4 illustrate the spatial distribution of population growth rates on a local scale. A greater demographic dynamism was observed over three decades (1971-1981, 1981-1991, 1991-2001). Demographic dynamics in the initial decade (1961-1971) led to a consolidation of the Athens' metropolitan area as the central country's node for population. Significant increases in the resident population have been observed in a very sparse way across rural Greece, especially in coastal districts and around the provincial head towns. 


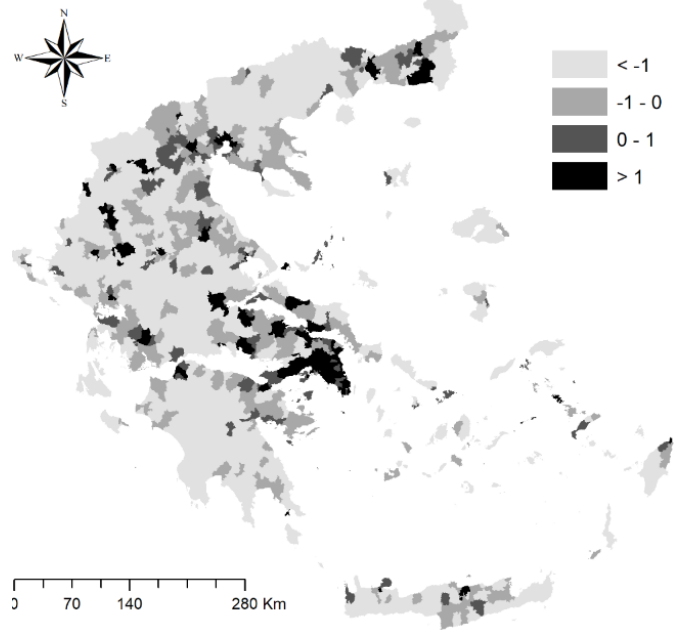

1961-1971

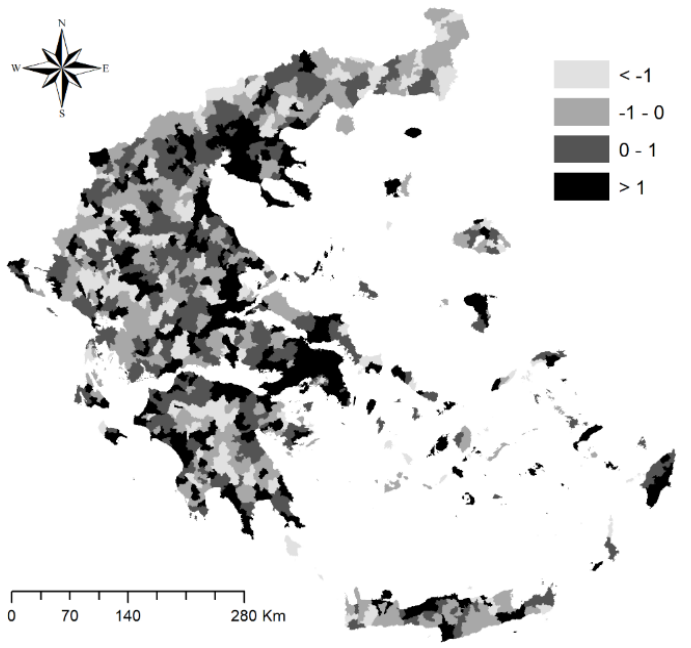

$1981-1991$

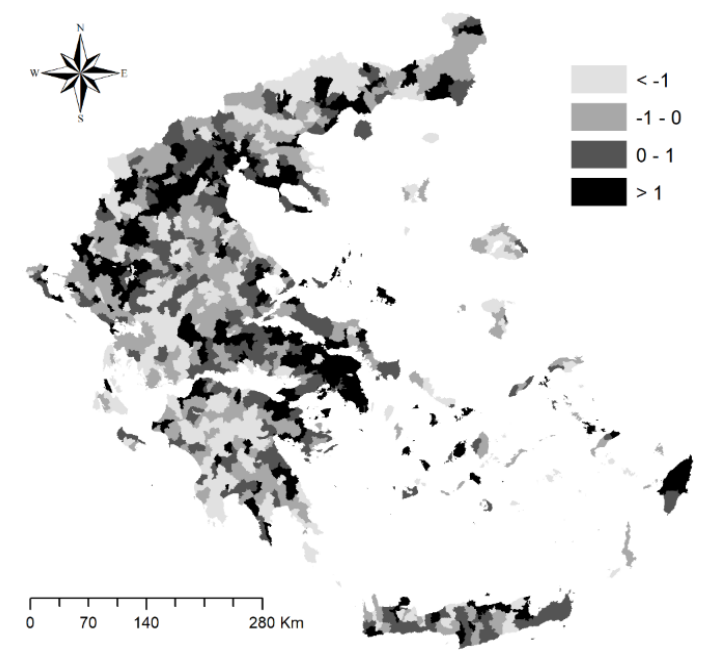

1971-1981

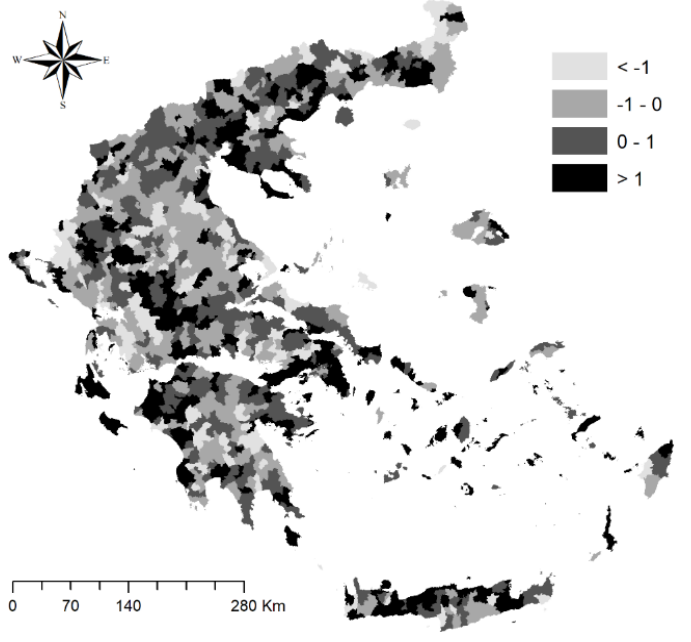

1991-2001

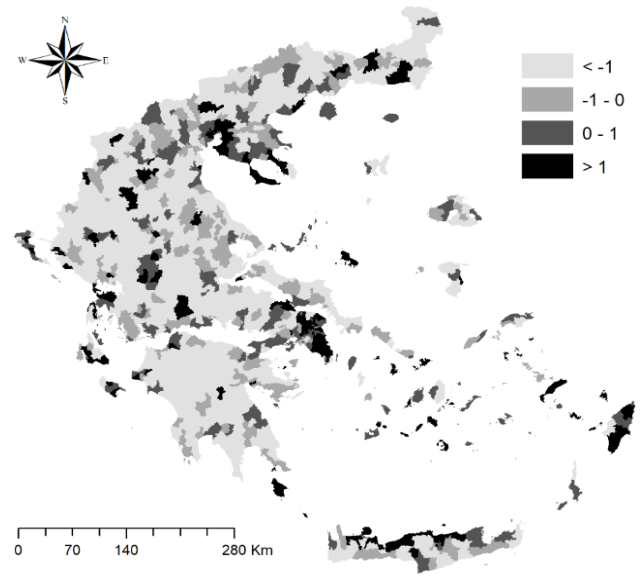

2001-2011

Figure 4. Annual population growth rate (\%) in Greek municipalities by time interval.

In the most recent decade (2001-2011), the greatest increases were observed outside the metropolitan area of Athens, mainly in Salonika's province, Crete, Rhodes, and in other accessible and medium density areas. However, some rural areas have also experienced a significant population increase. In the intermediate decades, population growth has been more pronounced almost everywhere. 
The internal districts of Thessaly and the Peloponnese, however, presented a rather stagnant population, even in these periods. Results of the analysis of the relationship between population density and growth over time were presented in Table 4.

Table 4. Distribution of two goodness-of-fit metrics of the relationship between population growth rate and density using linear and non-linear estimation by equation grade (from 1 to 5 ) for Greek municipalities $(\mathrm{n}=1034)$ by time interval, 1961-2011.

\begin{tabular}{cccccc}
\hline Country & 1 (Linear) & 2 (Square) & 3 (Cubic) & 4 (Polyn.) & 5 (Polyn.) \\
\hline \multicolumn{7}{c}{ Adjusted $R^{2}$} \\
$1961-1971$ & 0.153 & 0.179 & 0.254 & 0.277 & 0.281 \\
$1971-1981$ & 0.045 & 0.050 & 0.102 & 0.103 & 0.115 \\
$1981-1991$ & 0.008 & 0.009 & 0.080 & 0.082 & 0.091 \\
$1991-2001$ & 0.015 & 0.016 & 0.121 & 0.133 & 0.143 \\
$2001-2011$ & 0.124 & 0.167 & 0.214 & 0.227 & 0.229 \\
& \multicolumn{7}{c}{ Fisher-Snedecor F statistic } \\
$1961-1971$ & 186.9 & 112.1 & 116.9 & 98.6 & 80.5 \\
$1971-1981$ & 48.2 & 26.9 & 39.1 & 29.4 & 26.8 \\
$1981-1991$ & 8.6 & 4.7 & 29.9 & 23.1 & 20.6 \\
$1991-2001$ & 15.5 & 8.5 & 47.4 & 39.7 & 34.4 \\
$2001-2011$ & 145.6 & 103.5 & 93.7 & 75.7 & 61.0 \\
\hline
\end{tabular}

The $\mathrm{R}^{2}$ index was associated with a measure of the variance explained by each model, considering the relative degrees of freedom. The highest fit was observed for the first and last decade. The $\mathrm{R}^{2}$ index increased with the number of parameters, while the Fisher-Snedecor $\mathrm{F}$ test statistic assumed the maximum value systematically for the cubic model. This result has been confirmed for all the decades under study, suggesting the validity of the cubic model for the analysis of the relationship between urban concentration and population growth in Greece.

The estimation coefficients of the cubic model are shown in Table 5. Based on the coefficients of the relative equation, two critical density thresholds have been estimated on the basis of the cubic model; the first threshold indicates the specific density value above which (or below which) negative (or positive) population growth rates were more likely observed in Greek municipalities. As it is systematically high (above 1000 inhabitants $/ \mathrm{km}^{2}$ ), this density threshold was intended as a proxy of the effects of population concentration and urban congestion on demographic growth rates. The second threshold indicates the specific density value below which (or above which) negative (or positive) population growth rates were more likely observed in Greek municipalities. Being systematically low (above 20 inhabitants $/ \mathrm{km}^{2}$ ), this threshold was intended as a proxy of the effects of population dispersion, land abandonment and rural shrinkage on demographic growth rates.

Table 5. Equation coefficients (third-grade polynomials) using non-linear estimation (see Table 4) between population growth rate (dependent variable) and population density (independent variable) for Greek municipalities ( $\mathrm{n}=1034)$ by time interval, 1961-2011.

\begin{tabular}{cccccc}
\hline Parameter & $\mathbf{1 9 6 1 - 1 9 7 1}$ & $\mathbf{1 9 7 1 - 1 9 8 1}$ & $\mathbf{1 9 8 1 - 1 9 9 1}$ & $\mathbf{1 9 9 1 - 2 0 0 1}$ & $\mathbf{2 0 0 1 - 2 0 1 1}$ \\
\hline $\mathrm{a}_{0}$ & 0.3675 & 0.6082 & 0.5777 & 0.6685 & -0.0260 \\
$\mathrm{a}_{1}$ & -1.1298 & -1.1720 & -1.0098 & -1.1235 & -0.5252 \\
$\mathrm{a}_{2}$ & 0.6741 & 0.6626 & 0.5756 & 0.6101 & 0.4098 \\
$\mathrm{a}_{3}$ & -0.0974 & -0.0973 & -0.0884 & -0.0915 & -0.0690 \\
\hline
\end{tabular}

Based on these calculations, the (highest) density threshold distinguishing the positive and negative effects of urban concentration on population dynamics was estimated at 2800 inhabitants $/ \mathrm{km}^{2}$ in 1961 and decreased to 1300 inhabitants $/ \mathrm{km}^{2}$ in 2011 (Table 6). These thresholds correspond to positive population growth rates, decreasing progressively from $0.5 \%$ per year in $1961-1971$ to just over $0.2 \%$ in 
2001-2011. The (lowest) density threshold evidencing the negative effects of rural depopulation on population dynamics was instead estimated at a density of around 10-20 inhabitants $/ \mathrm{km}^{2}$; the relative population growth rate was around zero in the intermediate decades (1971-2001) and close to $-0.2 \%$ in the initial and final decade.

Table 6. Critical thresholds of population density and growth for urban congestion and depopulation estimated from best-fit models in Table 5, Greek municipalities ( $\mathrm{n}=1034)$ and time interval, 1961-2011.

\begin{tabular}{ccc}
\hline Time Window & Population Density (Inhabitants $\mathbf{~ k m ~}^{\mathbf{2}}$ ) & Annual Population Growth Rate (\%) \\
\hline & Urban congestion & \\
$1961-1971$ & 2800 & 0.50 \\
$1971-1981$ & 2500 & 0.45 \\
$1981-1991$ & 1600 & 0.31 \\
$1991-2001$ & 1400 & 0.29 \\
$2001-2011$ & 1300 & 0.23 \\
& Depopulation trap & \\
$1961-1971$ & 10 & -0.20 \\
$1971-1981$ & 12 & 0.00 \\
$1981-1991$ & 15 & 0.04 \\
$1991-2001$ & 20 & 0.06 \\
$2001-2011$ & 8 & -0.21 \\
\hline
\end{tabular}

\section{Discussion}

European urban areas have grown by $78 \%$ in the last half century, while resident population increasing by only 33\% [90]. Such changes have shaped inner cities, suburban districts and more peripheral rural areas $[11,77,78]$ leading to spatial disparities and demographic divides [60]. In turn, Southern European regions have experienced an intense cycle of urbanization-suburbanization-reurbanization, accelerated by a rapid demographic transition toward lowest-low fertility, higher life expectancy and immigration $[46,66,87]$. The original contribution of the present study lies in a diachronic analysis of long-term population trends (1961-2011) in Greek municipalities aimed at verifying density-dependent mechanisms of population growth at vastly different levels of population concentration, from hyper-compact and dense urban areas to depopulated rural districts. In these regards, local-scale settlement patterns in Greece consolidated the pre-existing metropolitan hierarchy centered on large cities, such as Athens and Salonika, similarly to what was observed in other Northern Mediterranean countries, such as Spain or Italy [58].

The variable density-growth thresholds identified in our study suggest that mechanisms of demographic growth typical of urban areas (i.e., a negative density-growth curve) involved an increasing number of peri-urban municipalities with less compact settlements and an intermediate level of population concentration $\left(>1300\right.$ inhabitants $\left./ \mathrm{km}^{2}\right)$. At the same time, mechanisms of growth typical of rural areas (i.e., a positive density-growth curve) were more specifically observed in locations far away from metropolitan regions, with medium-low values of population concentration (100-1300 inhabitants $\left./ \mathrm{km}^{2}\right)$ and higher variability in the relative growth rates. Finally, municipalities with a very low population density $\left(<100\right.$ inhabitants $\left./ \mathrm{km}^{2}\right)$ in depopulated or marginal locations, have displayed a mixed density-growth relationship, with heterogeneous and spatially variable patterns. In such contexts, demographic growth (or decline) was largely independent from the overall level of density, being influenced by other socioeconomic factors.

While identifying specific regimes at the local scale, the empirical results of this study outline the intrinsic characteristics of each local context and a substantial similarity in the relationship between population concentration and demographic growth across time and space [56]. Socio-demographic changes are mostly associated with economic agglomeration, being a key factor of land-use change and socioeconomic transformations $[3,8,25,68]$. Sequential waves of concentration and de-concentration of central cities, continuous expansion of suburbs and the abandonment of marginal and peripheral rural 
areas, have consolidated population density divides in Greece [10]. These processes are the base of complex-mainly non-linear-density-dependent mechanisms [58].

The empirical evidence presented in this study provides an original interpretation of population dynamics along the urban-rural gradient in a Southern European country. The results confirm the presence of density-dependent non-linear effects on the population growth rate in Greece. In particular, the proposed models highlight a critical threshold that discriminates between positive effects of urban concentration and negative effects of congestion on population growth rates. This threshold was estimated on density values ranging between 1000 and 3000 inhabitants per $\mathrm{km}^{2}$ along the study period. Such a threshold appropriately distinguishes medium-density contexts from high-density hyper-compact ones, where the effects of congestion seem to be more evident. From the point of view of the urban cycle, this threshold also distinguishes mature urban contexts, which have experienced compact-dense urbanization and rapid population growth (e.g., the central municipalities of Athens, Piraeus, and Salonika), from the surrounding municipalities under intense suburbanization, with evident growth potentials and urban spaces that can still be further developed. Critical density thresholds decreased over time, positioning at values around 1300 inhabitants $/ \mathrm{km}^{2}$ in 2011 (2800 inhabitants $/ \mathrm{km}^{2}$ in 1961). Such a decrease follows urban dynamics in the post-war period in Greece, with the subsequent urbanization of peripheral areas of the Attica region and the province of Salonika. The population growth rate corresponding to this density threshold also showed some variations over time, decreasing from $0.5 \%$ per year (1961) to $0.2 \%$ per year (2011). This decline follows a typical demographic trend in Greece, highlighting an equilibrium rate that converged towards a growth rate of around $0.2 \%$ per year.

Results of the empirical analysis also show a fairly heterogeneous and unpredictable density-growth relationship for levels of population concentration below 10-20 inhabitants $/ \mathrm{km}^{2}$. In other words, the positive impact of urban agglomeration on population growth was negligible in low-density rural contexts. This threshold remained relatively stable over time, being associated with zero (1971-2001) or slightly negative (1961-1971 and 2001-2011) growth rates. This highlights that rural shrinkage underlies particularly volatile demographic dynamics, which require stabilization policies aimed at promoting local development to counteract further depopulation. Considering both $\mathrm{R}^{2}$ and $\mathrm{F}$ statistics, the model's goodness-of-fit was rather variable over time, indicating that population density is only one-albeit important-factor influencing demographic growth in Greece. The highest model's performance was found for the first and last time windows, corresponding respectively to urban concentration (1961-1971) and rural depopulation (2001-2011).

These results indicate the relevant role of space in demographic dynamics. In this context, analysis of the density-growth relationship characterizes distinctive socioeconomic phases that reflect multiple factors of change at the regional scale $[53,54,69]$. While the negative relationship between urban concentration and population growth at higher densities reflects congestion externalities and a subtle process of peri-urbanization, the positive relationship between the same variables at intermediate densities may indicate the contribution of agglomeration factors to metropolitan growth observed since the 1960s in settlements with a density below 1000-3000 inhabitants $/ \mathrm{km}^{2}$ [91]. Stability over time in the relationship between urban concentration and the population growth rate was tested in this study with the secondary aim to identify and characterize distinctive phases within the country's urban-rural cycle. Internal (political, institutional and cultural issues) and external (economic globalization and socio-demographic change) factors have demonstrated to influence local-scale population dynamics shaping metropolitan hierarchies at a broader spatial scale [41,92,93]. Results of this study may definitely inform a comprehensive strategy for sustainable development, providing key information for urban planning and rural development $[31,32,94]$. Our study is likely the first to provide a sustainability-oriented (unifying) view of demographic dynamics linking urban growth in central places to population shrinkage in more marginal locations. 


\section{Conclusions}

Density-dependent mechanisms of population growth are of interest for urban and regional planning all over Europe [14,63,64,95-97]. These mechanisms reflect distinctive demographic dynamics at multiple spatial and temporal scales. Analysis of the empirical relationship between population density and demographic growth rates provided basic results clarifying density-dependent adjustments of population growth along the urban-rural gradient in a European country, evidencing demographic patterns typical of socioeconomic contexts with high and low density. Future research should better integrate empirical results of density-dependent regulation mechanisms in complex systems, comparing the results of different statistical approaches and theoretical models. Non-linear modeling and non-parametric statistical techniques considering spatial and temporal dynamics seem to be particularly appropriate in this direction. Geo-referenced databases with local-scale, up-to-date information encompassing relatively long time intervals, are the essential pre-requisite of any informed analysis of spatial regimes of population growth and the possible influence of scale and agglomeration.

Author Contributions: conceptualization, L.S. and M.C.; methodology, K.R. and R.S.; software, G.E. and S.C.; validation, S.C. and K.R.; formal analysis, L.S. and K.R.; investigation, M.C. and R.S.; resources, G.E. and M.C.; data curation, M.C. and R.S.; writing-original draft preparation, L.S. and M.C.; writing—review and editing, R.S. and L.S.; visualization, S.C.; supervision, K.R.; project administration, M.C.; funding acquisition, G.E. All authors have read and agreed to the published version of the manuscript.

Funding: This work was supported by a grant of the Ministry of Education of the Czech Republic, NPU I(LO1415).

Conflicts of Interest: The authors declare no conflict of interest.

\section{References}

1. Combes, P.P.; Duranton, G.; Gobillon, L. The identification of agglomeration economies. J. Econ. Geogr. 2011, 11, 253-266. [CrossRef]

2. Gardiner, B.; Martin, R.; Tyler, P. Does spatial agglomeration increase national growth? Some evidence from Europe. J. Econ. Geogr. 2011, 11, 979-1006. [CrossRef]

3. Haase, A.; Bernt, M.; Großmann, K.; Mykhnenko, V.; Rink, D. Varieties of shrinkage in European cities. Eur. Urban Reg. Stud. 2016, 2, 86-102.10. [CrossRef]

4. Tóth, G.; Nagy, Z. The world's economic centre of gravity. Reg. Stat. 2017, 6, 177-180.

5. Petrakos, G.C. Urban concentration and agglomeration economies: Re-examining the relationship. Urban Stud. 1992, 29, 1219-1229. [CrossRef]

6. Turok, I. Cities, regions and competitiveness. Reg. Stud. 2004, 38, 1061-1075. [CrossRef]

7. Combes, P.P.; Duranton, G.; Overman, H.G. Agglomeration and the adjustment of the spatial economy. Pap. Reg. Sci. 2005, 84, 311-349. [CrossRef]

8. Munafò, M.; Salvati, L.; Zitti, M. Estimating soil sealing at country scale - Italy as a case study. Ecol. Indic. 2013, 26, 36-43. [CrossRef]

9. Gavalas, V.S.; Rontos, K.; Salvati, L. Who becomes an unwed mother in Greece? Socio-demographic and geographical aspects of an emerging phenomenon. Popul. Spaceand Place 2014, 20, 250-263. [CrossRef]

10. Morelli, V.G.; Rontos, K.; Salvati, L. Between suburbanisation and re-urbanisation: Revisiting the urban life cycle in a Mediterranean compact city. Urban Res. Pract. 2014, 7, 74-88. [CrossRef]

11. Russo, A.P.; Serrano Giné, D.; Pérez Albert, M.Y.; Brandajs, F. Identifying and Classifying Small and Medium Sized Towns in Europe. Tijdschr. Voor Econ. En Soc. Geogr. 2017, 108, 380-402. [CrossRef]

12. Melo, P.C.; Graham, D.J.; Noland, R.B. A meta-analysis of estimates of urban agglomeration economies. Reg. Sci. Urban Econ. 2009, 39, 332-342. [CrossRef]

13. Solon, J. Spatial context of urbanization: Landscape pattern and changes between 1950 and 1990 in the Warsaw metropolitan area, Poland. Landsc. Urban Plan. 2009, 93, 250-261. [CrossRef]

14. Serra, P.; Vera, A.; Tulla, A.F.; Salvati, L. Beyond urban-rural dichotomy: Exploring socioeconomic and land-use processes of change in Spain (1991-2011). Appl. Geogr. 2014, 55, 71-81. [CrossRef]

15. Weilenmann, B.; Seidl, I.; Schulz, T. The socioeconomic determinants of urban sprawl between 1980 and 2010 in Switzerland. Landsc. Urban Plan. 2017, 157, 468-482. [CrossRef] 
16. Salvati, L. Agro-forest landscape and the 'fringe' city: A multivariate assessment of land-use changes in a sprawling region and implications for planning. Sci. Total Environ. 2014, 490, 715-723. [CrossRef]

17. Lee, R.D. Population dynamics of humans and other animals. Demography 1987, 24, 443-465. [CrossRef]

18. Fowler, C.W. Density dependence as related to life history strategy. Ecology 1981, 62, 602-610. [CrossRef]

19. Turchin, P. Rarity of density dependence or population regulation with lags? Nature 1990, 344, 660-663. [CrossRef]

20. Hopfenberg, R. Human Carrying Capacity Is Determined by Food Availability. Popul. Environ. 2003, 25, 109-117. [CrossRef]

21. Berryman, A.A. Principles of Population Dynamics and Their Application; Stanley Thornes: Cheltenham, UK, 1999.

22. Cohen, J.E. Human population: The next half century. Science 2003, 302, 1172-1175. [CrossRef] [PubMed]

23. Lima, M.; Berryman, A.A. Positive and negative feedbacks in human population dynamics: Future equilibrium or collapse? Oikos 2011, 120, 1301-1310. [CrossRef]

24. Galor, O.; Weil, D.N. From Malthusians stagnation to modern growth. Popul. Econ. Growth 1999, 89, $150-154$. [CrossRef]

25. Bosker, M. Growth, agglomeration and convergence: A space-time analysis for European regions. Spat. Econ. Anal. 2007, 2, 91-100. [CrossRef]

26. Baldini, R. The importance of population growth and regulation in human life history evolution. PLoS ONE 2015, 10. [CrossRef] [PubMed]

27. Lemelin, A.; Rubiera-Morollón, F.; Gómez-Loscos, A. Measuring urban agglomeration: A refoundation of the mean city-population size index. Soc. Indic. Res. 2016, 125, 589-612. [CrossRef]

28. Beale, C.L. Rural Depopulation in the United States: Some Demographic Consequences of Agricultural Adjustments. Demography 1964, 1, 264-272. [CrossRef]

29. Lutz, W.; Sanderson, W.; Scherbov, S. The end of world population growth. Nature 2001, 412, 543-545. [CrossRef]

30. Strulik, H. Learning-by-doing, population pressure, and the theory of demographic transition. J. Popul. Econ. 1997, 10, 285-298. [CrossRef]

31. Grafeneder-Weissteiner, T.; Prettner, K. Agglomeration and demographic change. J. Urban Econ. 2013, 74, 1-11. [CrossRef]

32. Beenstock, M.; Felsenstein, D. Marshallian theory of regional agglomeration. Pap. Reg. Sci. 2010, 89, 155-172. [CrossRef]

33. Kincses, Á.; Nagy, Z.; Tóth, G. Modelling the spatial structure of Europe. Reg. Stat. 2014, 4, 40-54. [CrossRef]

34. Boserup, E. Population and Technological Change: A Study of Long-Term Trends; University of Chicago Press: Chicago, IL, USA, 1981.

35. Price, D. Carrying Capacity Reconsidered. Population and Environment 1999, 21, 5-26. [CrossRef]

36. André, M.F. Depopulation, land-use change and landscape transformation in the French Massif Central. Ambio 1998, 27, 351-353.

37. Hoggart, K.; Paniagua, A. The restructuring of rural Spain? J. Rural Stud. 2001, 17, 63-80. [CrossRef]

38. Alados, C.L.; Errea, P.; Gartzia, M.; Saiz, H.; Escós, J. Positive and negative feedbacks and free-scale pattern distribution in rural-population dynamics. Plos One 2014, 9, 1-12. [CrossRef]

39. Beeson, P.E.; DeJong, D.N.; Troesken, W. Population growth in US counties, 1840-1990. Reg. Sci. Urban Econ. 2001, 31, 669-699. [CrossRef]

40. Lutz, W.; Qiang, R. Determinants of human population growth. Phil. Trans. R. Soc. B. Biol. Sci. 2002, 357, 1197-1210. [CrossRef]

41. Berliant, M.; Wang, P. Dynamic urban models: Agglomeration and growth. Contrib. Econ. Anal. 2004, 266, 531-581.

42. Rodriguez-Pose, A.; Fratesi, U. Between development and social policies: The impact of European Structural Funds in Objective 1 regions. Reg. Stud. 2004, 38, 97-113. [CrossRef]

43. Salvati, L.; Carlucci, M. The economic and environmental performances of rural districts in Italy: Are competitiveness and sustainability compatible targets? Ecol. Econ. 2011, 70, 2446-2453. [CrossRef]

44. Zitti, M.; Ferrara, C.; Perini, L.; Carlucci, M.; Salvati, L. Long-Term Urban Growth and Land Use Efficiency in Southern Europe: Implications for Sustainable Land Management. Sustainability 2015, 7, 3359-3385. [CrossRef] 
45. Varga, L.; Tóth, G.; Néda, Z. An improved radiation model and its applicability for understanding commuting patterns in Hungary. Reg. Stat. 2016, 6, 27-38. [CrossRef]

46. Zambon, I.; Serra, P.; Sauri, D.; Carlucci, M.; Salvati, L. Beyond the 'Mediterranean city': Socioeconomic disparities and urban sprawl in three Southern European cities. Geogr. Ann. Ser. Bhuman Geogr. 2017, 99, 319-337. [CrossRef]

47. Oueslati, W.; Alvanides, S.; Garrod, G. Determinants of urban sprawl in European cities. Urban Stud. 2015, 52, 1594-1614. [CrossRef]

48. Salvati, L.; Carlucci, M. Patterns of sprawl: The socioeconomic and territorial profile of dispersed urban areas in Italy. Reg. Stud. 2016, 50, 1346-1359. [CrossRef]

49. Partridge, M.D.; Rickman, D.S.; Ali, K.; Olfert, M.R. Do new economic geography agglomeration shadows underlie current population dynamics across the urban hierarchy? Pap. Reg. Sci. 2009, 88, 445-466. [CrossRef]

50. Portnov, B.A.; Schwartz, M. Urban clusters as growth foci. J. Reg. Sci. 2009, 49, 287-310. [CrossRef]

51. Salvati, L.; Gemmiti, R.; Perini, L. Land degradation in Mediterranean urban areas: An unexplored link with planning? Area 2012, 44, 317-325. [CrossRef]

52. Kabisch, N.; Haase, D. Diversifying European agglomerations: Evidence of urban population trends for the 21st century. Popul. Space Place 2011, 17, 236-253. [CrossRef]

53. Pili, S.; Grigoriadis, E.; Carlucci, M.; Clemente, M.; Salvati, L. Towards Sustainable Growth? A Multi-criteria Assessment of (Changing) Urban Forms. Ecol. Indic. 2017, 76, 71-80. [CrossRef]

54. Duvernoy, I.; Zambon, I.; Sateriano, A.; Salvati, L. Pictures from the Other Side of the Fringe: Urban Growth and Peri-urban Agriculture in a Post-industrial City (Toulouse, France). J. Rural Stud. 2018, 57, 25-35. [CrossRef]

55. Tapia, F.J.B.; Díez-Minguela, A.; Martinez-Galarraga, J. Tracing the evolution of agglomeration economies: Spain, 1860-1991. J. Econ. Hist. 2018, 78, 81-117. [CrossRef]

56. Crescenzi, R.; Luca, D.; Milio, S. The geography of the economic crisis in Europe: National macroeconomic conditions, regional structural factors and short-term economic performance. Camb. J. Reg. Econ. Soc. 2016, 9, 13-32. [CrossRef]

57. Lauf, S.; Haase, D.; Kleinschmit, B. The effects of growth, shrinkage, population aging and preference shifts on urban development-A spatial scenario analysis of Berlin, Germany. Land Use Policy 2016, 52, 240-254. [CrossRef]

58. Carlucci, M.; Grigoriadis, E.; Rontos, K.; Salvati, L. Revisiting an Hegemonic Concept: Long-term 'Mediterranean Urbanization' in between city re-polarization and metropolitan decline. Appl. Spat. Anal. Policy 2017, 10, 347-362. [CrossRef]

59. Kiochos, P.; Rontos, K. Urbanization and Large Cities in the Mediterranean Countries. Arch. Econ. Hist. 1999, 10, 1-2.

60. Mykhnenko, V.; Turok, I. East European cities-patterns of growth and decline, 1960-2005. International Planning Studies 2008, 13, 311-342. [CrossRef]

61. Paulsen, K. Geography, policy or market? New evidence on the measurement and causes of sprawl (and infill) in US metropolitan regions. Urban Stud. 2014, 51, 2629-2645. [CrossRef]

62. Rickman, D.S.; Wang, H. US regional population growth 2000-2010: Natural amenities or urban agglomeration? Pap. Reg. Sci. 2017, 96, S69-S90. [CrossRef]

63. Petrakos, G.; Rodríguez-Pose, A.; Rovolis, A. Growth, integration, and regional disparities in the European Union. Environ. Plan. A 2005, 37, 1837-1855. [CrossRef]

64. Di Feliciantonio, C.; Salvati, L. 'Southern' Alternatives of Urban Diffusion: Investigating Settlement Characteristics and Socio-Economic Patterns in Three Mediterranean Regions. Tijdschr. Voor Econ. En Soc. Geogr. 2015, 106, 453-470. [CrossRef]

65. De Rosa, S.; Salvati, L. Beyond a 'side street story'? Naples from spontaneous centrality to entropic polycentricism, towards a 'crisis city'. Cities 2016, 51, 74-83. [CrossRef]

66. Cuadrado-Ciuraneta, S.; Durà-Guimerà, A.; Salvati, L. Not only tourism: Unravelling suburbanization, second-home expansion and "rural" sprawl in Catalonia, Spain. Urban Geogr. 2017, 38, 66-89. [CrossRef]

67. Kasanko, M.; Barredo, J.I.; Lavalle, C.; McCormick, N.; Demicheli, L.; Sagris, V.; Brezger, A. Are European cities becoming dispersed? A comparative analysis of 15 European urban areas. Landsc. Urban Plan. 2006, 77, 111-130. [CrossRef] 
68. Grekousis, G.; Manetos, P.; Photis, Y.N. Modeling urban evolution using neural networks, fuzzy logic and GIS: The case of the Athens metropolitan area. Cities 2013, 30, 193-203.3. [CrossRef]

69. Colantoni, A.; Grigoriadis, E.; Sateriano, A.; Venanzoni, G.; Salvati, L. Cities as selective land predators? A lesson on urban growth, deregulated planning and sprawl containment. Sci. Total Environ. 2016, 545, 329-339. [CrossRef]

70. Cecchini, M.; Zambon, I.; Pontrandolfi, A.; Turco, R.; Colantoni, A.; Mavrakis, A.; Salvati, L. Urban sprawl and the 'olive' landscape: Sustainable land management for 'crisis' cities. GeoJournal 2019, 84, 237-255. [CrossRef]

71. Schneider, A.; Woodcock, C.E. Compact, dispersed, fragmented, extensive? A comparison of urban growth in twenty-five global cities using remotely sensed data, pattern metrics and census information. Urban Stud. 2008, 45, 659-692. [CrossRef]

72. Salvati, L.; Zambon, I.; Chelli, F.M.; Serra, P. Do spatial patterns of urbanization and land consumption reflect different socioeconomic contexts in Europe? Sci. Total Environ. 2018, 625, 722-730. [CrossRef]

73. Sato, Y.; Yamamoto, K. Population concentration, urbanization, and demographic transition. J. Urban Econ. 2005, 58, 45-61. [CrossRef]

74. Klasen, S.; Nestmann, T. Population, population density and technological change. J. Popul. Econ. 2006, 19, 611-626. [CrossRef]

75. Frick, S.A.; Rodríguez-Pose, A. Change in urban concentration and economic growth. World Dev. 2018, 105, 156-170. [CrossRef]

76. Ceccarelli, T.; Bajocco, S.; Perini, L.; Salvati, L. Urbanization and Land Take of High Quality Agricultural Soils-Exploring Long-term Land Use Changes and Land Capability in Northern Italy. Int. J. Environ. Res. 2014, 8, 181-192.

77. Biasi, R.; Colantoni, A.; Ferrara, C.; Ranalli, F.; Salvati, L. In-between Sprawl and Fires: Long-term Forest Expansion and Settlement Dynamics at the Wildland-Urban Interface in Rome, Italy. Int. J. Sustain. Dev. World Ecol. 2015, 22, 467-475. [CrossRef]

78. Kazemzadeh-Zow, A.; Zanganeh Shahraki, S.; Salvati, L.; Neisani Samani, N. A Spatial Zoning Approach to Calibrate and Validate Urban Growth Models. Int. J. Geogr. Inf. Sci. 2017, 31, 763-782. [CrossRef]

79. Giannakourou, G. Transforming spatial planning policy in Mediterranean countries: Europeanization and domestic change. Eur. Plan. Stud. 2005, 13, 319-331. [CrossRef]

80. Ostffeld, R.S.; Canham, C.D.; Pugh, S.R. Intrinsic density-dependent regulation of vole populations. Nature 1993, 366, 259-261. [CrossRef]

81. Mueller, L.D.; Guo, P.Z.; Ayala, F.J. Density-dependent natural selection and trade-offs in life history traits. Science 1991, 253, 433-435. [CrossRef]

82. Åström, M.; Lundberg, P.; Lundberg, S. Population dynamics with sequential density-dependencies. Oikos 1996, 77, 174-181. [CrossRef]

83. Waters, J.M.; Fraser, C.I.; Hewitt, G.M. Founder takes all: Density-dependent processes structure biodiversity. Trends Ecol. Evol. 2013, 28, 78-85. [CrossRef] [PubMed]

84. Berry, B. City size distributions and economic development. Econ. Dev. Cult. Chang. 1961, 9, 573-588.

85. Turchin, P. Long-term population cycles in human societies. Ann. N. Y. Acad. Sci. 2009, 1162, 1-17. [CrossRef] [PubMed]

86. Hamilton, M.J.; Burger, O.; DeLong, J.P.; Walker, R.S.; Moses, M.E.; Brown, J.H. Population stability, cooperation, and the invasibility of the human species. Proc. Natl. Acad. Sci. USA 2009, 106, 12255-12260. [CrossRef]

87. Salvati, L.; Serra, P. Estimating rapidity of change in complex urban systems: A multidimensional, local-scale approach. Geogr. Anal. 2016, 48, 132-156. [CrossRef]

88. Cohen, J.E. Population growth and earth's human carrying capacity. Science 1995, 269, 341-345. [CrossRef]

89. Duncan, S.R.; Duncan, C.J.; Scott, S. Human population dynamics. Ann. Hum. Biol. 2001, 28, 599-615. [CrossRef]

90. European Environment Agency. Urban Sprawl in Europe-The Ignored Challenge; European Environmental Agency: Copenhagen, Denmark, 2006; Available online: https://www.eea.europa.eu/publications/eea_report_ 2006_10 (accessed on 14 February 2020). 
91. Rontos, K.; Grigoriadis, E.; Sateriano, A.; Syrmali, M.; Vavouras, I.; Salvati, L. Lost in protest, found in segregation: Divided cities in the light of the 2015 "Oxı" referendum in Greece. Cityculture Soc. 2016, 7, 139-148. [CrossRef]

92. Mathur, V.K.; Stein, S.H.; Kumar, R. A dynamic model of regional population growth and decline. J. Reg. Sci. 1988, 28, 379-395. [CrossRef]

93. Glaeser, E.L.; Gottlieb, J.D. The wealth of cities: Agglomeration economies and spatial equilibrium in the United States. J. Econ. Lit. 2009, 47, 983-1028. [CrossRef]

94. Han, B.; Wang, R.; Tao, Y.; Gao, H. Urban population agglomeration in view of complex ecological niche: A case study on Chinese prefecture cities. Ecol. Indic. 2014, 47, 128-136. [CrossRef]

95. Galor, O.; Weil, D.N. Population, technology, and growth: From Malthusian stagnation to the demographic transition and beyond. Am. Econ. Rev. 2000, 90, 806-828. [CrossRef]

96. Zhang, J. Urbanization, population transition, and growth. Oxf. Econ. Pap. 2002, 54, 91-117. [CrossRef]

97. Lutz, W.; Testa, M.R.; Penn, D.J. Population density as a key factor in declining human fertility. Popul. Environ. 2006, 28, 69-81. [CrossRef]

(C) 2020 by the authors. Licensee MDPI, Basel, Switzerland. This article is an open access article distributed under the terms and conditions of the Creative Commons Attribution (CC BY) license (http://creativecommons.org/licenses/by/4.0/). 